\title{
A Preparatory Program for Young Adults on the Autism Spectrum: Identity Exploration and Self-advocacy
}

\author{
Shiri Pearlman-Avnion, Shirley Kenny, and Inbal Vortman-Shoham
}

\begin{abstract}
At the stage of emerging adulthood, young adults on the autism spectrum need specific interventions to help them realize their potential. The "Avnei Derech" preparatory program was designed to respond to that need, by means of an individually tailored plan for each participant. In light of the innovative nature of the model, the team engages in continuous review and reformulation of their work, focusing on the goal of promoting the participants' developmental tasks. For this purpose, it is necessary first to understand the general characteristics of emerging adulthood and of autism, and especially, of autistic young adults with high-function autism. Former studies shed light on the characteristics of autism characteristics, but did not examine their impact on the developmental tasks of emerging adulthood. In this research, we focused on the task of exploration during emerging adulthood and the different aspects of delay in this process associated with autism. We conducted three case studies, which demonstrate the general structure of the "Avnei Derech" preparatory program. The main purpose of the study was to define and conceptualize the means of exploration required by people with autism in order to become acquainted with oneself and the environment, as part of identity formation and the development of self-advocacy skills.
\end{abstract}

Index Terms-Autism, identity and self-advocacy, intervention program, young adulthood.

\section{INTRODUCTION}

The term "emerging adulthood" was first suggested by Arnett [1] to describe the age period from the late teens through the late twenties. This developmental phase is characterized by instability in different life spheres, such as education, career, intimacy, and worldviews. It is an important stage of making choices and important decisions about one's future. One of the main developmental tasks at this time is that of exploration, a process in which the person learns about him or herself and the surroundings through experience, cognitive work, and processing data gathered. The goal and process of this investigation differ from those typical of adolescence, in that they are future oriented. Based on their study of young adult exploration among Israelis, Cinamon, Rich, and Gross-Spector [2] concluded that "the findings indicating that young adults investigate the fields they are involved in more than others emphasizes the

Manuscript received August 28, 2015; revised January 6, 2016. The Avnei Derech Preparatory program is supported in part by the Israeli Ministry of Social Affairs and Social Services, and with the kind support of the Wohl Legacy foundations, the Ted Arison Family Foundation and the Sobell Family Foundation.

Shiri Pearlman-Avnion is with the Department of Education, Tel-Hai Academic College, Israel (e-mail: shiripearlmanavnion@yahoo.com).

Shirley Kenny and Inbal Vortman-Shoham are the Avnei Derech La' Haim, Israeli Charity, Kachal, Israel (e-mail: info@avneiderech.org.il). importance of encouraging them to try different kinds of work and fields of study before making choices" [2]. They also noted the need to develop means of exploration that allow young people to learn about the self and people around them, such as peers groups, family, and friends.

The "Avnei Derech" program("Avnei Derech" means in Hebrew "Milestones", MS) was designed to respond to this need and enable the exploration process and identity construction for young adults who possess the unique characteristics of autism: impaired theory of mind, difficulties in emotional processing of events in order to construct autobiographical memories, executive functions deficit, pragmatic language impairment, and symptoms that affect the ability to understand and participate in simple and complex social interactions.

The difficulties of young adults with autism spectrum disorder at this time of life are manifest not only in avoiding age-appropriate experiences, but also in impairment of the ability to reflect, understand, and ascribe meaning to these experiences, which is crucial for the construction of self. The MS program is guided by a model that encourages exploration by means of experiencing different situations and arrangements with mediation of opportunities. The entire process involves wondering, critique, and ascribing meaning, with emphasis on insights derived from formation of one's identity, in general, and internalization of one's identity as a person with autism, in particular.

\section{A. Young Adulthood}

The concept of emerging adulthood or ongoing adulthood refers to the phase between adolescence and early-to-middle adulthood [1]. It is characteristic of young adults in their early twenties in industrial societies, without children, who do not own their homes or have the resources required for full independence. Actually, Arnett discussed the period between the ages of 18-25, when young adults become more independent and can try different forms of living. This is a new demographic concept, involving "identity explorations... instability, the self-focused age, the age of feeling in-between" [3]. Studies of the possible continuation of this phase have shown that this would require social conditions that allow for non-binding experiences and the postponement of the decisions characteristic of adulthood [3], [4]. C te [4] also confirmed the extension of the adolescent period, but argued that this does not reflect new developmental needs, but rather a logical adaptation to new life circumstances that have developed over recent decades, which produce tension. He emphasized the need for intervention.

More than any other age period, this phase allows a process of exploration and examination in the fields of love and partnership, work and career, and worldviews. The 
development of identity that begins during adolescence reaches a peak during emerging adulthood. Identity development is a dynamic process of self-determination and self-understanding, which are crucial to the ability to "direct, give meaning to, and present the self" [5]. Its importance derives from its effect on the ways in which a person acts and responds in the personal and social contexts. The main criteria that determine the sense of reaching adulthood are the emergence and the stabilization of traits such as the ability to make independent decisions and take responsibility for oneself [3]. Research has shown that emerging adulthood varies among individuals and is affected by environmental factors, such as completion of compulsory frameworks (such as school or military service) and moving toward the situation of making decisions about and for oneself. Thus, for instance, in the United States, this process is typically experienced in the late teens to the mid-twenties; in Israel (where most citizens serve in the army in the late teens and early twenties), the usual age range is from the early twenties to early thirties, and it is characterized by making choices about the future.

For parents, this period may include gestures such as giving their children more privacy, trust, and appreciation. The recognition that this is a special period affords the youngsters increasing independence in the crucial processes of forming a sense of identity and exploration. Living with one's parents may have a negative impact on the young adult's adjustment to autonomy, and can delay parents' recognition of their children as adults. Living in different households may help young adults and their parents acknowledge the changing character of their relationship [6], [7].

During this period, there is a slight decrease in reliance on familial bonds, with more emphasis on personal choice. The freedom to choose and experience is sometimes accompanied by a feeling of confusion and uncertainty. The effort to create an independent, separate identity also involves redefinition of relationships with significant others, such as parents, as separate people and not just in terms of their parental role [8]. The individuation processes of young people in this phase are complex; they require redefinition of relationships, as well as fears regarding one's ability to perform daily task independently, the significance of support systems, and the relations between them [9]. Scholars have argued that redefinition of the relationship with the parents and reconstruction of the relations in the nuclear family are crucial to the young adult's ability to develop meaningful interpersonal relationships, such as romantic partnerships, later in life [10], [11], and to adopt healthy emotional conduct as an adult [12]. The critical aspect of the parental support derives from the role of parents as adult figures who assist in the containment and processing of different life events, negative or positive, and in the development of understanding that enables the acquisition of skills for better functioning in adulthood [12].

Research conducted during the last two decades has revealed that the brain does not stop growing in adolescence, and that high-level cognitive functions continues to develop during this phase [13]-[15]. Brain plasticity during sensitive periods needs environmental experiences in order to affect brain circuitry [14]. Brain structures and connectivity develop, enabling more processing of emotional and social data [16],
[17]. The areas of the brain that are responsible for planning and risk management also undergo critical development at this time, thus contributing significantly to the greater maturity of young adults compared with teens. People at this age are expected to be less impulsive in their decision-making and to rely more on planning and assessment of situations [18].

This development is essentially cognitive: it involves the more complex forms of thinking required in complex societies. However, it is also important to note the interrelationship of this prominent cognitive development with significant changes in sense of self and reflective ability. Research on the aspects that link autobiographical memory to the creation and representation of a coherent self highlights the importance of the period of emerging adulthood. This creation and representation process involves reconstruction of the autobiographical memory, which serves as a knowledge base on the working self and the emerging narrative of the young adult [19]. In the last two decades, research on brain anatomy and physiology has introduced the use of magnetic instruments to map brain activity and learn about the brain development and plasticity and the atypical development of the autistic brain. The findings have been associated with the behavioral symptoms of autism - poor executive functions, failure to express empathy, deficits in theory of mind derived from Mirror Neurons' System dysfunction, and the cognitive processing of complex information [16], [20]. Recent research has raised questions about the typicality of the construction process of autobiographical memories in autism, due to deficit in processing and integration of emotional and social experiences [21].

The process of exploration in emerging adulthood focuses on three main areas: love/partnership, work/career, and life views. It differs from the exploration typical of adolescence in purpose and in nature. It is future oriented, with a focus on acquiring life experience in work, relationships, abilities, and skills for the sake of future possibilities. Exploration is the art of navigating between possible selves that might develop into a more coherent and constructed self [22]. Social status affects the exploration, producing diverse possibilities for satisfaction and fulfillment.

In addition to the above, many young adults report feelings of loneliness during their exploration. The absence of the opportunities to explore might speed up the individuation process, but such a result would derive from instability and difficulty in developing a coherent identity [2].

In a typical maturation process, the encounter with others generates a reflective process. Individuals undergo the process of separation and individuation in a social context, in which they reflect on others and on what they are experiencing. Furthermore, the observation of how others reflect on them affects their internal cognition processes [5], [23]. The number of possibilities supposedly available to the individual increases significantly, as does the level of uncertainty, because things are not as stable and steady as in the past. Young people in today's society face ambiguity regarding social requirements and their position visá $\mathrm{v}$ is their environment. In the past, vocational stability provided security at work; nowadays, individuals need to adapt to frequent employment changes, to be proactive, and to take 
responsibility. Work is not only a way for people to express themselves, but also a means of involvement in the community. Career development is part of the dynamic development of the self. Each experience is assimilated into one's identity, adding to the former personal core. Erickson [24] referred to stages in the process of development, such as adolescence, when the question of identity plays a more central and dominant role. He emphasized that identity in based on the individual's encounter with the others. Later in life, personal development is also mediated by interpersonal encounters and the meanings attributed to these interactions, which construct identity. Interpersonal interaction can produce validation by means of reflection, idealization of the other, and observation of another as someone you want to be (thus creating a motivation factor). This may lead to validation of things that happen to the individual, ascribing meaning learned from others even though it was not originally there. The exploration process actually reflects the identity task; it is carried out partly internally, but is nurtured by the presence of the other. Therefore this process represents a challenge for people with autism.

\section{B. Characteristics Associated with Autism}

Autism is commonly accompanied by loneliness and isolation, limited social interaction, and a restricted range of social modeling. Another key feature of autism is impairment of theory of mind (ToM), that is, the understanding of different world of thoughts, intentions, and desires of others, and the ability to differentiate them from one's own and attribute them to different mental and psychological states. Autism also includes impairment of meta-cognition, that is, the knowledge of others' thoughts and feelings; this concept is similar to ToM, but broader. These impairments hinder the process of using feedback from the environment in constructing one's identity.

Research findings have indicated that children on the autism spectrum demonstrate less initiative and involvement in social interactions compared with their peers. The interactions they do engage in are functional, aimed at fulfilling personal needs. The way they initiate such interactions also differ; they are characterized by gestures that are not situation-appropriate (lack of eye contact, manner of discourse, and the like). In typical adolescence, abstract forms of thinking develop; thus the social difficulties of people with autism are intensified at this stage. This is also a time when social rules become complex and non-explicit, and adolescents use higher levels of sarcasm and cynicism in their language. The difficulty of adolescents with autism to understand gestures, facial expressions, and the prosodic elements of speech encumbers their understanding of the implicit meaning of the language their peers use. The impaired understanding of nonverbal cues can lead to violation of space and prevent an understanding of the adolescent context of friendship, which extends beyond concrete and functional needs to include just "hanging out" [25].

Recent research on the impairment of ToM and joint attention (the ability to share a focus of attention with another person through nonverbal behavior) reexamined earlier findings that children on the autism spectrum lack joint attention and ToM. The results indicated that people with high-functioning autism performed equally to their peers in relevant laboratory tests, but implementation in everyday life situations was impaired [26]. Despite the ability to see and recognize the mental state of the other and one's own situation, there was difficulty in the spontaneous expression of these abilities in situations that were not controlled and mediated. In light of these difficulties in monitoring and controlling joint attention and ToM in everyday performance, their interpersonal conversations were inappropriate. During adolescence and adult life, these skills become crucial, especially in the peer group, where conversation skills are vital to social integration [25].

Emotional understanding and empathy typically develop during the second year of life. The development of more complex feelings depends upon the ability to understand intention, the assumption of responsibility, and the acceptance of social norms. Understanding the complexity of an emotional state is derived from comparison of one's behavior with the social norms and the experience that this comparison generates. Thus it requires the ability to understand the social reactions to a behavior and to place it in an emotional context. For such a process to take place, one must possess an understanding of the concept of "self." Understanding the self and the ability to recognize emotional states are crucial to the ability to feel and express empathy. Research has shown that children with autism tend to express less empathy than their peers do. The impaired capability of children and teens with autism to react to the feelings of others leads to their social exclusion by peers [27].

Young children with high-functioning autism are aware of their social impairment. In the company of peers, they acknowledge their differences from their peers and their social isolation. Consequently, in addition to loneliness, they also experience a sense of rejection. The short-term distress leads long-term low self-esteem. In fact, the awareness of people with high-functioning autism puts them at higher risk for depression and isolation than those with lower levels of functioning. Some people with autism perceive their loneliness only in terms of isolation (being alone). These people might report loneliness without the negative feelings that usually accompany it, such as fear, anger, helplessness, sadness, and alienation. It is very important to understand how people with high-functioning autism perceive friendship. Studies have shown that children with high-functioning autism tended less to identify meanings of affection (such as sharing feelings, sharing private information, trust, and helping each other) as important aspects of friendship than their typically developed peers did. Most of the friendships they reported were functional, based on common interests and activities. This perception of friendship suggests that these individuals would feel more loneliness in the absence of a social network of peers, regardless of the development of dyadic relationships [25].

\section{Young Adulthood of People on the Autism Spectrum}

Young adults on the autism spectrum experience loneliness of two kinds: social loneliness, defined as a "negative state experienced as a result of group isolation, or the absence of a large peer group or network of acquaintances" [25]; and 
emotional loneliness, which refers to the negative experience of isolation in dyadic relationships, or the absence of a specific dyadic or close personal relationship. The main negative feelings of loneliness are lack of empathy and a feeling of exclusion that can lead to alienation [25]. Relationships fulfill six basic needs: attachment, social integration, reliable alliance, guidance, reassurance of worth, and the opportunity for nurturance [28].

Research has found that emotional loneliness is associated with a low level of relationships with attachment, and social loneliness is correlated with lack of social integration [25]. High-functioning young adults on the autism spectrum reported higher levels of loneliness related to the absence of a social network than to the absence of dyadic relationship, compared with peers. Although their reported general stress level was similar to that of their peers, the increased sense of sadness and loneliness (which correlated with the absence of a dyadic relationship) among people with high-functioning autism was lower. Another interesting finding was a significant correlation of high levels of social and dyadic isolation with anxiety and depression within the control group compared with the absence of such a correlation in the group of people with autism. One possible explanation is the ability of the latter to make and maintain dyadic relationships, which leads to their experience of "some elevated levels of sadness and loneliness with respect to existing dyadic relationships, resulting in higher ratings of sadness and loneliness associated with low levels of dyadic isolation" [25]. Thus even low levels of relationships of both kinds lead to high levels of emotional stress.

Hendricks and Wehman [6] reviewed researches on transition plans of youngsters on the autism spectrum from high school to adult life in terms of education, employment, independent living, and community integration. They found that transition programs and designated training could significantly improve the integration in the community and vocational capabilities of individuals with autism, but cited the need, because of the high heterogeneity in the spectrum, for a variety of services and individually tailored support. The research also indicated that even though many students had a structured transition program and constructed plan for the future in high school, less than $33 \%$ of them participated actively in meetings about their future and only three percent of these led the discussion. As for the rest, a special school team was dominant in determining their plan, and at least one parent was present in more than $90 \%$ of the meetings. The presence of the student in such meetings is crucial to learning about oneself and planning the future. According to many of the researchers in Hendricks and Wehman review [6], it is possible to increase student involvement in various ways, such as visually (assistive technology), socially and organizational. The purpose of such transition plans is to teach students the skills required to function as adults. The programs are student-focused and function-oriented, with concentration on communication and social skills, employment, leisure, and household. However, because a unique plan is tailored for each student, it is difficult to evaluate these programs. The studies reviewed in Hendricks and Wehman did not discuss the issues of identity exploration or construction of self.
In order to attain the goals of their transition plans, most of the students need a broad system of services and support. All the programs reviewed mentioned the need for continuation of the services and support after graduation, in light of the recognition of autism as a lifelong disability for which adults also require assistance. The different plans also specified how and where these skills should be taught in order to assure significant impact and enable their implementation throughout life. An unexpected finding was that the special education programs offered more opportunities and placed more emphasis on learning skills in environment, based on "normal" life in community, compared with the regular education system, where students with autism experienced less activities and learning outside the classroom.

Studies have shown that it is advantageous for people with autism to leave home after completing high school. Parents whose children remained in the home reported higher stress levels and higher care giving demands, and those whose children had left home reported high satisfaction, more participation in the community, and a higher quality of life. However, despite the broad range of possibilities for accommodation, only a small percentage of the young adults lived independently or in supported living arrangements; most of them remained in their parents' homes. A study conducted in Sweden revealed that $64 \%$ of people diagnosed with autism spectrum disorder (ages 16-36) were living independently, but they were still "described as dependent on their parents for support" [6]. The support and interventions that improved independence most focused on self-help skills and participation in everyday activities. The authors concluded that it is important to enable young adults a full range of support and living arrangements. Nevertheless, they noted that all such individuals require lifelong support; in the absence of such services, their families must play a central role in responding to their needs. Therefore, it is also important to provide families with information about autism and training as well as community support programs. The relative effectiveness of the different strategies for developing independence and self-sufficiency is still unclear, as few have undergone scrupulous examination; however, it is clear that they are very important to living in the community and to the reduction of stress levels among caregivers [6].

Most adolescents on the autism spectrum are not aware of their specific diagnosis. Even though some recognize that they differ from their peers, there is wide variance in their levels of self-awareness and acceptance of being "disabled" [29]. Studies have shown that most teenagers with autism do not perceive their diagnosis as a disability [30], and some scholars have also argued that autism is not a disability but rather a neuro-cognitive variation [31]. Whichever the case, these individuals require suitable services, which are currently provided only for "special needs."Research has highlighted the importance of understanding and accepting the diagnosis and specific difficulties and their severity [32]. Camarena and Sarigiani [29] found a higher degree of self-esteem among teenagers who recognized their disorder and could accurately describe their difficulties and the differences they faced. It is important to help people with autism develop awareness, acceptance, and understanding of the disability and its difficulties, and to provide them with 
tools for identity construction and definition that enable them to own their autistic identity as part of their overall emerging self. A mature process of understanding their disability, accepting difficulties, and highlighting abilities allows young adults to better navigate adult life and use self-advocacy skills intelligently [33]-[35].

Research has also shown the importance of self-advocacy skills in the successful transition to adult life systems, and particularly higher education [29], [36]. Studies of the successful integration of students with learning disabilities have shown that the students who demonstrated higher success were those with higher levels of self-awareness, acceptance, and understanding of their disability, but whose disability did not define their identity [37]. Carmarena \& Sarigiani [29] interviewed autistic youth and their parents about their aspirations for higher education. The participants raised mainly social and institutional challenges and concerns, and did not address issues regarding the readiness of the adolescents for academic study. Due to the intellectual abilities and strength of people with high-functioning autism, higher education has become a critical measure for the evaluation of self-esteem. When graduating from high school, young adults and their parents have concrete targets regarding higher education and an academic degree, which they perceive as the means of attaining experience that is vital for adult life. Although their teachers evaluation are high relative to others in the class, their academic accomplishments are among the lowest in the class due to difficulties in performing age-appropriate functional skills, and their self-efficacy is challenged by knowledge of the resources needed to manage in the academic world [6], [30]. The barriers to higher education extend beyond academic aspects, and include, as noted, the inability to live independently, fit in socially, adapt to frequent and unexpected changes, undertake academic tasks, self-advocate with service providers who are unaware of their disability, and so forth. To obtain and employ support and interventions, these students must be true proactive agents of their own change. The support process should focus on helping the individuals define their goals, explore and produce a realistic comprehension of their capabilities and potential. The program should include special assistance and strategies for the academic and non-academic realms of life. In light of the broad intersection of the different life spheres, holistic training and guidance in life skills are appropriate [6], [29].

Experience has shown that despite their challenges, autistic people are capable of working in many types of jobs, from supported employment to the free market. Supported employment offers different types of personal support to improve the participation, salaries, and the quality of life of people with disabilities [6]. Garcia-Villamisar and Hughes [38] found improvement in cognitive function after placement in supported employment. Although research has shown the advantages of community employment, the vast majority of people on the autism spectrum are still unemployed. The employment rate of young adults with autism in the United States is estimated at $25 \%$. The ratio between those who work in competitive employment and those who work in sheltered or voluntary jobs is 1 to 3. Among adults with Asperger's syndrome, the participation rate is lower than expected considering their intellectual abilities; only $20 \%$ are employed and $10 \%$ of these in competitively jobs [6]. As in the academic area, the obstacles in the world of work also involve difficulties adapting to the social and inexplicit requirements of the job. Higher education does not contribute to better participation in the employment market. Factors that have been found to improve successful implementation are interpersonal and communication skills, the ability to manage Stereotyped behavior patterns, and use of strategies to increase compatibility with the job. The recommendations for achieving this include experience in different jobs in the competitive market, in order to learn vocational skills and gain positive work experience [6].

A transition program should also involve the community in which the participants want to live, in order to provide opportunities for them to integrate socially and develop active, productive relationships in the framework of community activities. Community models that allow the continuation of support and training have been shown to yield higher participation rates. Effective integration requires the implementation of skills in different environments and the ability to effectively operate and navigate among activities, agents, and institutions [6]. These socialization skills are difficult to master. All this highlights the importance of community-based training in an environment that provides and mediates opportunities, along with the cognitive work of construction of the self.

This literature review demonstrates the diverse issues involved in the successful integration of young adults with high-functioning autism in different life spheres. It also indicates the dynamic nature and interface of different life spheres, the mutual effects of experiences in different social roles, and their impact on the ability to produce and maintain a coherent perception of self, as well a semotional coping resources [39], [40]. The MS preparatory program places strong emphasis on all these. The aim of the current study was to use case studies from the first year of the program to analyze how the program addressed the issues raised in the literature, and how it served the processes required by young adults on the autism spectrum in the transition to adult life. We hypothesized that despite the unique characteristics of the program developed for each individual participant, we would find a general pattern of correspondence between attainment of the goals and the emerging model of practices developed in the program.

\section{METHOD}

When the first year of the preparation program operation ended, we chose three cases for qualitative analysis. The choice of cases was based on methodical interviews with all staff members, designated to demonstrate the themes mentioned above. Each of the case studies presented is based on documentation of weekly sessions with the participant, and the individual supervision process protocol.

\section{ANALYSIS: THE CASE STUDIES}

\section{A. Michal}


Michal was a 24-year-old woman diagnosed on the autistic spectrum, accompanied by emotional difficulties. Michal had a long history of difficulties fitting in (at school, during army service, at work, and in employment rehabilitation). The process with Michal began by building her trust in the program environment and in herself. She had difficulties with the concept of "placement";she didn't want to be "placed" by others. Michal continually checked her boundaries and tested the trust of the staff. For example, she tested how much each staff member trusted and believed in her, allowed her to make her own choices (and even mistakes), and supported her even when she failed repeatedly. Michal had trouble accepting herself and believing that she had good qualities. It was hard for her to see that in some areas, her performance was as good as that of her peers. At the same time, she internalized a gradual process of separation from her parents and began to address her disappointments with herself without worrying about their reaction. After a year in the MS program, Michal was able to contain a disagreement with her parents, make her own choices, and take responsibility for their execution and consequences. Michal's parents underwent a parallel process in the program's parents group, which helped them undergo separation, as well.

In light of the program's proximity to a college and the encouragement of participants to take academic courses, Michal applied for an academic degree program even though she didn't have the qualifications required. In light of her difficulty sitting in class, she was also unable to complete prerequisite courses (she refused to take medication to improve her attention). Michal expected some authority to tell her she couldn't join the academic program. As a first step, the MS staff worked on expanding Michal's options, focusing on helping her find alternatives. They helped her examine what she needed for admission to the degree program (with the intention that this would help her find an alternative route herself). In parallel, they also helped her explore the possibility of studying a different subject; consequently, Michal enrolled for free courses in the community setting, in which she prepared a few presentations.

The next step was to expand Michal's experiences. The community education courses required her to sit in class for long hours and to acquire and implement study skills and to see herself as a fully committed student. When the academic year began, Michal took her first academic course in the department she was interested in. The funding of the course by MS was subject to her fulfilling all the course requirements, just like any other student. This condition reflected the staff's belief in her. At the beginning of the semester, a staff member supervised all aspects of her studying, including outside the classroom. Michal passed the course with a B-. Her parents encouraged her to accept that accomplishment, but Michal felt she could do better and decided to sit for a retest; indeed, she achieved a much higher grade the second time. In the next semester Michal took two courses, and the staff were less involved. She assumed the responsibility for studying, with assistance from the staff in material and time management. Michal is now about to begin the degree program. She is aware of her difficulties, capabilities, responsibility, and resources for help.

Michal began looking for a job on her own, but was unsuccessful. Based on her positive experience and trust in the staff regarding studies, she was able to ask the staff for assistance, to use the help she was given, and to manage this assistance. Coping with failure as well as accomplishments, Michal was able to develop more complex and enabling self-esteem, and to recognize that she was successful at some things and less so at other.

Michal is now employed in a temporary job. It does not fit her professional aspirations perfectly, but she is mature enough to accept that. She understands that this is one step toward her professional future. For the first time in her life, she is taking full responsibility for her employment.

\section{B. Tamir}

Tamir is a 23-year-old man, diagnosed for high-functioning autism, with emotional difficulties. When Tamir arrived at MS, he objected to just about everything there: being labeled as a person with autism, the use of money (which differed from his former place of residence, where spending was collective), and more. Tamir used strategies of reduction and avoidance and tended toward a partial view of the world. For example, he avoided using a calendar so he would not have to deal with the responsibility of remembering and completing his tasks. In working with Tamir, the staff members had to understand the extreme importance of respecting his pace and tendencies and of knowing precisely what phase he was in. The work with Tamir began with management of his living environment, that is, his apartment at MS. Tamir tended to berate others in order to raise his self-esteem. He also belittled primary goals, saying they weren't important ("Why do I need to live in a clean environment?"), as well as the added value he might gain through the staff members. At first, he repeatedly declared, "I shouldn't be here," or "I'm just giving it a chance so later I won't feel I missed out on something."

In the second phase, the work with Tamir focused on his understanding that staying at MS was up to him, and therefore good for him. He was asked to reaffirm his decision to participate (rather than just obeying his parents). Acknowledging his difficulties led to his belief that he could accomplish something by being in the program. Confronting the question of whether he could gain something from staying helped him gain trust in the staff.

The moment Tamir made the decision to participate in the program, the work focused on guidance in the vocational domain. As noted, Tamir initially rejected the notion of working for money ("Why do people have to work for money? I don't need money in order to live"). Once he developed trust of the staff he became more open-minded and willing to analyze what he was experiencing. He admitted that his rejection of the concept of earning money by working stemmed from fear of interaction with his superiors at work, and concern that he might not succeed or deserve the money. This realization enabled him to accept assistance; he began to share his difficulties, weaknesses, and fear of failure. In parallel to beginning the experience of work, Tamir also began taking academic courses and studying for the written driving test. Tamir is now open to identifying the domains in which he needs assistance, asking for it, and managing it. Once Tamir stopped avoiding his difficulties, he was able to identify his strengths: learning capabilities, management 
skills, using money, and strong resources for supporting others.

\section{Lotem}

Lotem was a 21-year-old woman with high-functioning autism. When she arrived at the MS program, Lotem expressed a wide gap between her will and need for relationships - friendship, romance, and sexual relations and her poor social skills, such as understanding social cues, empathy, and respecting the feelings of others. The staff members and participants were initially wary about acting naturally in her presence, because she reacted with tremendous anxiety and aggression.

The first step in working with Lotem was to build her basic trust in the environment. After that, the joint work, conducted when she was calm, focused on expanding her range of possible interpretations and acquiring strategies for self-comprehension. The staff members also taught Lotem about different kinds of friendships, and helped her implement this theoretical knowledge in actual life. She learned how to use the staff members as mediators; they helped her develop age-appropriate social skills and learn about how her actions affected others. The staff members help her analyze and understand social interpretations (her own and those of others). She learned to ask others (the MS staff and participants) for help in finding possible explanations and acquiring new skills and strategies that did not yet come naturally to her.

Lotem achieved vast improvement, but she still finds it difficult to control and manage her new skills when she feels stressed. She has progressed particularly in her management of relationships. There is a notable reduction in her uncontrolled reactions, which previously interfered with her academic efforts (she is now enrolled in a BA program). She has also developed as mall circle of friends at the college. She is able to advocate for her needs, but still needs to learn to make requests without expecting a full and immediate response. Within the MS program, Lotem is beginning to see the larger social picture and to produce multiple possible interpretations and reactions in her relationships. She has learned to map out her life and to manage and control stress factors so they don't paralyze her.

In addition, in the past, Lotem tried constantly to initiate sexual relations through social networks, without proper guidance and with great naivety. With the help of the staff(in workshops on healthy sexuality, understanding online cues, recognizing warning signs, etc.), she learned new skills regarding intimacy. As a result, Lotem now conducts herself more safely and suffers less frustration. The new skills she has acquired help her avoid the emotional storms and experiences of rejection that she encountered in the past. In light of her experience of honest and respectful communication, she now takes responsibility for her initiatives, and is able to evaluate the potential emotional cost of her choices.

Academic exams served Lotem as a good reality check regarding her priorities. Lotem realized that during the exam period she had to reserve resources for studies, regulate and postpone other activities such as initiating and maintaining of intimate relationships, which require extensive time and emotional resources.

\section{SUMmARY AND CONCLUSIONS}

The three case studies of participants in the MS preparatory program for young adults on the autism spectrum revealed different aspects of the exploration of emerging adulthood. This process of seeking and producing knowledge about oneself is part of identity construction. The participants accumulated experiences that widened their perspectives regarding the developmental tasks they confronted, their sense of self, and the alternatives available to them. This was accompanied by an expansion of their knowledge about the world and interests, recognition and mediation of alternatives, and an honest examination of personal competence. The cases presented provide some insight into the process during the first year in the two-year program.

MS consists of intensive work regarding autism, helping each individual identify difficulties and deficits and providing tailored responses for each individual to fulfill his or her potential. It is aimed at developing each participant's means of self-advocacy, understanding of the environment, and recognition of required assistance.

The MS program includes a workshop aimed at helping the participants accept their disability. This includes clarification of the difficulty that some participants have with the social stigma ofautism, as well as their self-perception as people on the autism spectrum. Extensive teaching and discussion is devoted to the components and the subjective meanings of autism for each individual. The program is intended to promote a mature process of understanding the disability, accepting the difficulties, and emphasizing the capabilities, in order to help these young adults navigate better through the adult life spheres and successful implement their newly acquired skills of self-advocacy [33]-[35]. Great emphasis is also placed on training the participants in decision making and assuming responsibility for the consequences of their choices, as well as intensive cognitive processing of these experiences with staff members, in order to create a coherent narrative. The development of a coherent personal narrative (and sometimes even a more accurate and realistic retelling of the past) enable more realistic self-efficacy, better understanding of the self, and gradual construction of a higher, more stabilized and more realistic self-image.

Research has indicated higher levels of self-awareness among young adults who recognized and could accurately describe the difficulties and distinctions that constituted significant challenges in their lives. Great importance was attributed to self-advocacy skills and a good transition to adult life and especially, higher education [29]. Studies have shown that the young adults who succeeded in integrating into general society best were those who demonstrated greater self-awareness, acceptance, and understanding of their disabilities, without using them to define their identity [37].

The combination of learning and practical experience in the MS program equips young adults on the autism spectrum with useful tools for realizing their abilities and aspirations and upgrading their personal narrative by means of reflection and learning, along with greater understanding of their strengths and weaknesses. All these afford them better and more effective competence in self-advocacy and improved social integration in the community. 


\section{ACKNOWLEDGMENT}

The authors would like to thank the Wohl Legacy Foundations for their support to the Avnei Derech La'Haim (Translation from Hebrew: Milestones for Life) Charity programs under the Maurice and Vivienne Wohl Initiative for Young Adults on the Autism Spectrum.

\section{REFERENCES}

[1] J. J. Arnett, "Emerging adulthood: A theory of development from the late teens through the twenties," American Psychologist, vol. 55, no. 5, pp. 469-480, 2000.

[2] R. G. Cinamon, Y. Rich, and M. Gross-Spector, "Exploration characteristics during young-adulthood: the case of young israelis," Research founded by the Gandyr Foundation, 2012.

[3] J. J. Arnett, "Emerging adulthood: What is it and what is it good for?" Child Development Perspectives, vol. 1, no. 2, pp. 68-73, 2007.

[4] J. Cote, Arrested Adulthood: The Changing Nature of Maturity and Identity in the Late Modern World, New York: New York University Press, 2000.

[5] E. P. Schachter and Y. Rich, "Identity education: A conceptual framework for educational researchers and practitioners," Educational Psychologist, vol. 46, no. 4, pp. 22-238, 2011.

[6] D. R. Hendricks and P. Wehman, "Transition from school to adulthood for youth with autism spectrum disorders: review and recommendations," Focus on Autism and Other Developmental Disabilities, vol. 24, no. 2, pp. 77-88, 2009.

[7] B. Persson, "Brief report: A longitudinal study of quality of life and independence among adult men with autism," Journal of Autism and Developmental Disorders, vol. 30, pp. 61-66, 2000.

[8] J. J. Arnett, "Emerging adulthood: Understanding the new way of coming of age," in Emerging Adults in America: Coming of Age in the 21st Century, J. J. Arnett and J. L. Tanner, Eds., Washington, DC, American Psychological Association, 2006, pp. 3-19.

[9] L. L. Holstrom, D. A. Karp, and P. S. Gray, "Why laundry, not hegel? Social class, transition to college, and pathways to adulthood," Symbolic Interaction, vol. 25, no. 4, pp. 437-462, 2002.

[10] W. S. Aquilino, "Family relationships and support systems in emerging adulthood," Emerging Adults in America: Coming of Age in the 21st Century, Washington, D.C., American Psychological Association, 2006, pp. 193-217.

[11] A. C. Jensen, S. D. Whiteman, K. L. Fingerman, and K. S. Birditt, "'Life still isn't fair': Parental differential treatment of young adults siblings," Journal of Marriage and Family, vol. 75, pp. 438-452, 2013.

[12] T. A. Dumas, H. Lawford, and T. T. Tieu, "Positive parenting in adolescence and its relation to low point narration and identity status in emerging adulthood: A longitudinal analysis," Developmental Psychology, vol. 45, no. 6, pp. 1531-1544, 2009.

[13] J. A. Giedd, J. Blumenthal, N. O. Jeffries, F. X. Castellanos, H. Liu, A. Zijbenbos, T. Paus, A. C. Evans, and J. L. Rapoport, "Brain development during childhood and adolescence: A longitudinal MRI study," Nature Neuroscience, vol. 2, pp. 861-863, 1999.

[14] T. K. Hensch and P. M. Bilimoria, "Re-opening windows: Manipulating critical periods for brain development," Cerebrum, vol. 11, July-August, 2012.

[15] J. L. Tanner and J. J. Arnett, "The emergence of 'emerging adulthood': The new life stage between adolescence and young adulthood," in Handbook of Youth and Young Adulthood: New Perspectives and Agendas, A. Furlong, Ed., New York, Routledge, 2009, pp. 39-45.

[16] M. Iacoboni and M. Dapretto, "The mirror neuron system and the consequences of its dysfunction," Nature Reviews Neuroscience, vol. 7, December, pp. 942-951, 2006.

[17] J. H. Williams, A. Whiten, T. Suddendorf, and D. I. Perrett, "Imitation, mirror neurons and autism," vol. 25, no. 4, 2001.

[18] H. Pharo, C. Sim, M. Graham, J. Gross, and H. Hayne, "Risky business: Executive function, personality, and rrckless behavior during adolescence and emerging adulthood," Behavioral Neuroscience, vol. 125, no. 6, pp. 970-978, 2011.

[19] M. A. Conway, "Memory and the self," Journal of Memory and Language, vol. 53, pp. 594-628, 2005.

[20] M. K. Belmonte, G. Allen, A. Beckel-Mitchener, L. M. Boulanger, R. A. Carper, and S. J. Webb, "Autism and abnormal development of brain connectivity," The Journal of Neuroscience, vol. 24, no. 42, pp. 9228-9231, 2004.
[21] R. S. Brezis, "Memory integration in the autobiographical narratives of individuals with autism," Frontiers in Human Neuroscience, vol. 9, no. 76, pp. 1-4, 13 February 2015.

[22] S. Cross and H. Markus, "Possible selves across the life span," Human Development, vol. 34, pp. 230-255, 1991.

[23] H. Flum and A. Kaplan, "Identity formation in educational settings: A contextualized view of theory and research in practice," Contemporary Educational Psychology, vol. 37, no. 3, p. 240-245, 2012.

[24] E. H. Erikson, Identity: Youth and Crises, New York: Norton, 1968.

[25] E. E. Merkler, "The experience of isolation and loneliness in young adults with high-functioning autism," Ph.D. dissertation, Dep. Psych. North Carolina Univ., Chapel Hill, 2007.

[26] A. M. Scheeren, M. Rosnay, H. M. Koot, and S. Begeer, "Rethinking theory of mind in high-functioning autism spectrum disorder," Journal of Child Psychology and Psychiatry, vol. 54, no. 6, pp. 628-635, 2013.

[27] L. Travis, M. Sigman, and E. Ruskin, "Links between social understanding and social behavior in verbally able children with autism," Journal of Autism and Developmental Disorders, vol. 31, no. 2, pp. 119-130, 2001.

[28] E. DiTommaso and B. Spinner, "Social and emotional loneliness: A reexamination of weiss' typology of loneliness," Personality and Individual Differences, vol. 22, pp. 417-427, 1997.

[29] P. M. Camarena and P. A. Sarigiani, "Postsecondary educational aspirations of high-functioning adolescents with autism," Focus on Autism and Other Developmental Disabilities, vol. 24, no. 2, pp. 115-128, 2009.

[30] H. Molloy and L. Vasil, Asperger Syndrome, Adolescence, and Identity: Looking Beyond the Label, New York: Jessica Kingsley, 2004.

[31] S. Baron-Cohen, "Is asperger syndrome necessarily referred to as a disability?" Focus on Autism and Other Developmental Disabilities, vol. 17 , pp. 186-191, 2002

[32] E. L. Roberts, S. Ju, and D. Zhang, "Review of practices that promote self-advocacy for students with disabilities," Journal of Disability Policy Studies, vol. 4, 2014.

[33] S. E. Eckes and T. A. Ochoa, "Students with disabilities: Transitioning from high school to higher education," American Secondary Education, vol. 33, no. 3, pp. 6-20, 2005

[34] C. A. H. Sahlen and J. P. Lehmann, "Requesting accommodations in higher education," Teaching Exceptional Children, vol. 38, no. 3, pp. 28-34, 2006

[35] S. Lukose, "The transition to college for students with disabilities in new york state," Career Development and Transition for Exceptional Individuals, vol. 23, no. 2, pp. 223-235, 2000.

[36] E. M. Ankeny and J. P. Lehmann, "Journey toward self-determination Voices of students with disabilities who participated in a secondary transition program on a community college campus," Remedial and Special Education, vol. 34, no. 4, pp. 279-289, 2011.

[37] N. J. Spekman, R. J. Goldberg, and K. L. Herman, "Learning disabled children grow up: A search for factors related to success in the young adult years," Learning Disabilities Research and Practice, vol. 7, pp. 161-170, 1992.

[38] D. García-Villamisar and C. Hughes, "Supported employment improves cognitive performance in adults with autism," Journal of Intellectual Disability Research, vol. 51, no. 2, pp. 142-150, 2007.

[39] J. R. Sneed, F. Hamagami, J. J. McArdle, P. Cohen, and H. Chen, "The dynamic interdependence of developmental domains across emerging adulthood," Journal of Youth and Adolescence, vol. 36, no. 3, pp. 351-362, 2007.

[40] S. Shulman, B. Laursen, and D. J. Dickson, "Gender differences in the spillover between romantic experiences, work experiences, and individual adjustment across emerging adulthood," Emerging Adulthood, vol. 2, no. 1, pp. 36-47, 2014.

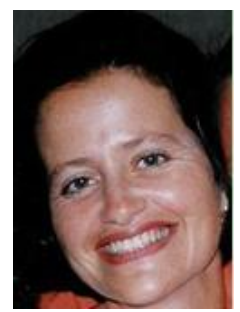

Shiri Pearlman-Avinion was born in Israel. Her B.A is in psychology and art history, the Department of Psychology, Haifa, Israel; the M.A. in cognitive psychology, Dept. of Psychology, Haifa University; the Ph.D. from Haifa University. The title of her dissertation is "Sociability and language use among people with development disabilities: Social and informative aspects of theory of mind." Now she is a lecturer at the Department of Education and the Department of Psychology, in Tel-Hai College, Upper Galilee, Israel. Parallel to researching she owns a private clinic. Dr.Shiri Pearlman-Avinion's interests are autism, cognition, theory of mind, and educational psychology. 


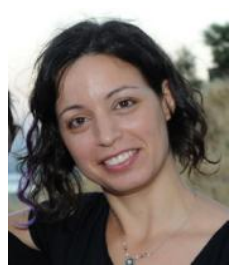

Shirley Kenny was born in Israel. Her B.A. is in political science and sociology, Faculty of Social Sciences, University of Haifa, Israel. Shirley had accomplished her studies in career development mentoring, the Department of Education, Tel-Aviv University, Israel. After several years in the field of leisure services for children with special needs, she became more involved in the non-formal education. Together with Inbal Vortman-Shoham, she established milestones for life association for young adults on the Autism spectrum. Now she is co-managing the association and its new services development.

Shirley Kenny's interests are in high function autism spectrum, career development and service development to ensure the autonomy and wellbeing of independent adults on the autism spectrum.

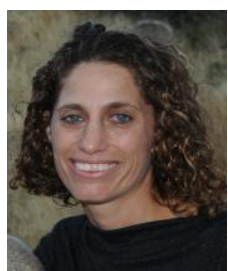

Inbal Vortman-Shoham was born in Israel. Her B.A is in special education and archaeology, the Department of Education and the Department of Archaeology, University of Haifa, Israel. Inbal worked with the Jewish National Fund's Green Horizons young leadership group in a variety of capacities for a decade. She was program coordinator for the Northern region and of the National Service program. One of her biggest achievements at the JNF was creating and running the Green Horizon's program for children with special needs. At 2010, together with Shirley Kenny, she established milestones for life association for young adults on the autism spectrum. Now she is co-managing the association and its preparatory program-the Avnei Derech Mechina. Inbal Vortman-Shoham's interests are in high function autism spectrum, professionals and staff development, and social entrepreneurship. 